\title{
LÓGICAS DE EXCLUSÃO/INCLUSÃO DOS PROCESSOS EDUCATIVOS NO CONTEXTO PRISIONAL FEMININO
}

\author{
Maria Celeste Fernandes Souza ${ }^{1}$ \\ Eunice Maria Nazareth Nonato ${ }^{2}$ \\ Maria Gabriela Parenti Bicalho ${ }^{3}$
}

\begin{abstract}
RESUMO: $\mathrm{O}$ artigo discute a educação escolar em instituiçóes prisionais exclusivamente femininas e apresenta resultados de um estudo que analisou as experiências educacionais de mulheres em situação de aprisionamento em quatro instituiçóes de Minas Gerais. O material empírico foi produzido por meio de um formulário com dados sobre o perfil socioeconômico respondido por 196 mulheres; entrevistas com os responsáveis pela oferta educativa; análise dos projetos pedagógicos; e entrevistas com 11 mulheres. Os dados foram analisados com o aporte teórico da discussão das categorias exclusão/inclusão e revelam processos interdependentes desse binômio que antecedem e configuram a situaçáo de privaçáo de liberdade, ao mesmo tempo em que forjam expectativas futuras.
\end{abstract}

Palavras-chave: Educação escolar. Prisão. Gênero. Exclusão/inclusão.

\section{LOGICS OF EXCLUSION/INCLUSION OF EDUCATIONAL PROCESSES IN THE FEMININE PRISIONAL CONTEXT}

\begin{abstract}
The article discusses the school education in exclusively female prisons and presents the results of a study that analyzed the educational experiences of women in imprisonment situation in four Minas Gerais institutions. The empirical material was produced by means of a form containing data on the socioeconomic profile answered by 196 women; interviews with those responsible for educational offer; analysis of pedagogical projects; and interviews with 11 women. The data were analyzed with the theoretical support of the discussion of the categories of exclusion/inclusion and reveal interdependent processes of this dual role which precede and shape the situation of deprivation of liberty, while forging future expectations.
\end{abstract}

Keywords: School Education. Prison. Gender. Exclusion/inclusion.

\footnotetext{
${ }^{1}$ Universidade Vale do Rio Doce (UNIVALE), Programa de Pós-Graduação em Gestão Integrada do Território - Governador Valadares (MG), Brasil. E-mail: celeste.br@gmail.com

${ }^{2}$ UNIVALE, Programa de Pós-Graduação em Gestão Integrada do Território - Governador Valadares (MG), Brasil. E-mail: eunicenazarethe@hotmail.com

${ }^{3}$ Universidade Federal de Juiz de Fora - Campus Governador Valadares - Governador Valadares (MG), Brasil. E-mail: mgbicalho@hotmail.com

Fonte de financiamento: Conselho Nacional de Desenvolvimento Científico e Tecnológico - CNPq DOI: 10.1590/ES0101-73302016158634
} 


\title{
LES LOGIQUES D'EXCLUSION/INCLUSION DES PROCESSUS D'ÉDUCATION DANS LE CONTEXTE DU SYSTÈME PÉNITENTIAIRE FÉMININ
}

\begin{abstract}
RESUME: L'article discute l'enseignement scolaire dans les prisons pour femmes et présente les résultats d'une étude sur les expériences éducatives des femmes emprisonnées dans quatre institutions de l'état de Minas Gerais. Comme stratégie de recherche, un formulaire sur le profil socio-économique a été répondu par 196 femmes ; des entretiens ont été realisés avec les responsables de l'offre de l'enseignement, bien que l'analyse des projets pedagogiques et des entretiens avec d'autres 11 femmes. Les données ont été analysées avec le soutien théorique des catégories d'exclusion et d'inclusion et montrent des processus interdépendants qui précèdent et façonnent la situation de privation de liberté, tout en forgeant des attentes futures.
\end{abstract}

Mots clés: L'enseignement scolaire. Prison. Genre. Exclusion/inclusion.

\section{Introdução: contexto do estudo e aportes teóricos}

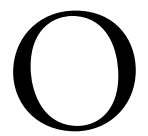

direito à educação de pessoas em situação de privação de liberdade, hoje reconhecido em documentos legais, tem origem nos movimentos sociais e nas reflexóes teóricas nos campos da educação e dos direitos humanos. A preocupação presente no campo da Educação de Pessoas Jovens e Adultas (EJA) sobre os sujeitos do processo educativo ecoa em estudos e documentos sobre a prisão (CARREIRA, 2009; IRELAND, 2011; JULIÃO, 2013a, 2013b; BRASIL, 2014).

No cenário internacional, destacam-se dois marcos legais: a Declaração Universal dos Direitos Humanos, aprovada na Assembleia Geral da Organização das Naçóes Unidas (ONU) em 1948, e a declaração sobre os direitos das pessoas reclusas, proclamada pela ONU em 1990. Ambas influenciaram o desencadeamento, no Brasil, de discussões acerca da educação em espaços de privação de liberdade.

Nesse cenário, a Lei de Execução Penal Brasileira - LEP de 1984 contemplou a educação como componente que atribui à pena o caráter ressocializador e instituiu a assistência à educação, que abarca a instruçáo escolar e a formação profissional (BRASIL, 1984). A Constituição Federal de 1988 reafirma a igualdade de condiçóes para o acesso e a permanência na escola (BRASIL, 1988), e a Lei de Diretrizes e Bases da Educaçáo Nacional no 9.394/96 assegura à população jovem e adulta o direito de ter considerados seus interesses e necessidades, mediante açóes integradas e complementares por parte do poder público na efetivação da oferta (BRASIL, 1996). Outros documentos importantes nesse cenário são as Diretrizes Nacionais para a Oferta de Educação para Jovens e Adultos em Situação de Privação 
de Liberdade (BRASIL, 2010) e a modificação na LEP (Lei no 12.433/201), que inclui a educação como fator de remição de parte do tempo da sentença condenatória de prisão (BRASIL, 2011).

Portanto, em função de articulações nacionais e internacionais, e do estabelecimento de um conjunto de leis, é possível afirmar que, nos últimos anos, a discussão da educação no espaço prisional teve avanços significativos (JULIÃO, 2013a, 2013b). Entretanto, a efetividade dessa discussão não se encontra assegurada. Ainda que fundamental, a oferta de vagas não é suficiente, e faz-se necessário discutir também a organizaçáo dos processos educativos e os diversos elementos que os compóem em sua complexidade: organização curricular, metodologias de ensino, relaçôes entre os sujeitos do processo educacional, formaçáo docente (JULIÃO, 2013b).

A fim de contribuir para a compreensão dessa realidade, este estudo analisou as experiências educacionais vivenciadas por mulheres privadas de liberdade em quatro instituiçóes prisionais exclusivamente femininas de Minas Gerais: duas APACs (Associação de Proteção e Assistência aos Condenados), um Presídio e um Complexo Penitenciário. A metodologia do estudo incluiu a realização de visitas às instituiçóes; entrevistas com os responsáveis pelas ofertas educacionais nesses espaços (um diretor e três pedagogas); análise de projetos pedagógicos; aplicação de formulário com perguntas relativas ao perfil socioeconômico destinado a todas as mulheres, e respondido por 196 delas; e entrevistas semiestruturadas realizadas com 11 mulheres.

A análise do objeto de pesquisa exige uma abordagem que reconheça os diferentes níveis e as diferentes perspectivas das experiências educativas que as mulheres vivenciam em situação de privação de liberdade. Encontramos nas categorias inclusão e exclusão aporte teórico que permite uma leitura coerente com a complexidade desses processos. Martins $(1997,2002)$ afirma não existir exclusão, e sim vítimas de processos sociais excludentes. Tal posiçâao baseia-se em uma perspectiva sociopolítica e contrapóe-se à ideia economicista que tem servido de escopo para justificar a questáo da exclusão, que na sociedade capitalista passa a ser uma regra estruturante.

(...) todos nós, em vários momentos de nossa vida, e de diferentes modos, dolorosos ou não, fomos desenraizados e excluídos. É própria dessa lógica de exclusão a inclusão. A sociedade capitalista desenraiza, exclui, para incluir, incluir de outro modo, segundo suas próprias regras, segundo sua própria lógica. $\mathrm{O}$ problema está exatamente nessa inclusão (MARTINS, 1997, p. 32).

Ainda para Martins (2002), as estratégias do modelo econômico adotadas de forma globalizante no sistema capitalista não são muitas vezes compatíveis com o bem-estar coletivo. Isso gera um desenvolvimento anômalo que não se manifesta somente pelas privações e exclusóes dos bens que o próprio 
capitalismo produz e dissemina, mas, principalmente, pelas estratégias de sobrevivência por meio das quais "os pobres teimam em fazer parte daquilo que não os quer senão como vítimas e beneficiários residuais de suas possibilidades" (MARTINS, 2002, p. 9).

A mesma sociedade que exclui também inclui e integra, cria formas desumanas de participação. Essa anomalia, no entanto, ocorre dentro de uma totalidade social contraditória e crítica, parte de um processo social histórico. Entender a exclusão como fato consumado e irremediável é negar a dinamicidade e as possibilidades advindas da relação dialética da realidade. Nesse sentido, Dupas (1999) aponta a relação exclusão versus inclusão como inerente ao sistema capitalista e como uma das contradiçóes que o nutrem, posto que

apesar do desemprego estrutural o capitalismo garante continuamente mercados (inclusão) que estavam à margem do consumo por falta de renda. Os maiores crescimentos de várias empresas têm sido registrados nos países periféricos onde se encontram parte dos mercados mais pobres. (DUPAS, 1999, p. 40)

Møller e Hespanha (2002) contribuem para o alargamento dessa discussão ao afirmarem que padróes de inclusão/exclusão resultam da combinação de diferentes dimensôes de participação social (trabalho, rendimento, redes sociais, cultura, política, lazer etc.). Disso resulta o fato de uma pessoa se encontrar incluída em alguns domínios da vida social, e não necessariamente em todos. Assim, indivíduos não são sempre incluídos "automaticamente", e o processo de inclusão pode resultar das estratégias desenvolvidas pelas pessoas para fortalecerem a participação na vida social. Além disso, esses autores defendem a ideia de que a exclusão/inclusão possui concepção dinâmica, multidimensional e relacional, podendo uma pessoa, durante sua trajetória de vida, fazer emergir dessa dinamicidade relacional infinitas possibilidades de novos sistemas e subsistemas. Segundo os autores, é infindável o número de subsistemas em uma sociedade funcionalmente diferenciada. Além disso, emergem constantemente novos sistemas e subsistemas, em qualquer momento da trajetória da vida de um indivíduo, sem que se tenha de estar necessariamente incluído em todos os sistemas, ou excluído de todos eles.

As categorias de inclusão e exclusão permitem questionamentos que podem contribuir para a análise da educaçâo no sistema prisional: de que direitos as pessoas privadas de liberdade estão excluídas, além do direito à liberdade? Que relaçôes de inclusão/exclusão se constituem na condição de aprisionamento, e na educação nesse contexto? Nessa perspectiva, há que se considerar também as diferenças de gênero, que implicam em diferentes modos de ser e viver (na prisão e fora dela) para mulheres e homens. Se no aprisionamento estabelecem-se processos de exclusão e inclusão, muitos outros estão relacionados ao contexto de aprisionamento, como antecedentes e consequências dessa condição. 
É a partir dessa perspectiva que analisaremos os dados coletados na pesquisa que subsidia este artigo: o perfil das mulheres em situação de privação de liberdade em quatro instituiçóes prisionais exclusivamente femininas do estado de Minas Gerais, as condiçóes da oferta educacional nessas instituiçóes e os sentidos atribuídos à escolarização pelas mulheres que nelas estudam.

\section{Perfil das mulheres presas: retratos da exclusão e da inclusão}

A população prisional feminina no Brasil apresenta uma curva ascendente no período de 2000 a 2014: 37.380 mulheres encontram-se encarceradas, e o crescimento dessa população foi de " $567,4 \%$, enquanto a média de crescimento masculino [maioria da populaçáo prisional], no mesmo período, foi de $220,20 \%$ " (BRASIL, 2014, p. 5). O perfil dessas mulheres é constituído por características que podem ser lidas como produtos de processos de exclusão dos bens e direitos sociais e como resultantes da inclusão em certa condição feminina: "são jovens, têm filhos, são as responsáveis pela provisão do sustento familiar, possuem baixa escolaridade, são oriundas de extratos sociais desfavorecidos economicamente e exerciam atividades de trabalho informal em período anterior ao aprisionamento" (BRASIL, 2014, p. 5).

O perfil socioeconômico encontrado neste estudo, coletado pelos formulários respondidos por 196 mulheres das 4 instituiçôes prisionais, reforça essa caracterização. Na faixa etária entre 19 e 27 anos, encontram-se 38\% delas ( 75 mulheres); enquanto 23\% ( 45 mulheres) têm entre 28 e 34 anos. Portanto, $61 \%$ das mulheres pesquisadas tinham até 34 anos.

Com relação à escolaridade, também se confirma o perfil das mulheres em situação de privação de liberdade no país, conforme apresentado no Gráfico 1.

Observa-se, portanto, que essas mulheres se enquadram, majoritariamente, no "Ensino Fundamental Incompleto" (52\% ou 101 mulheres) e no "Ensino Médio Incompleto" ( $26 \%$ ou 50 mulheres), o que corrobora os dados nacionais: " $50 \%$ das mulheres encarceradas não concluíram o ensino fundamental" (BRASIL, 2014, p. 26). Ao constatar esse baixo índice de escolarização e o fato de que $78 \%$ das mulheres pesquisadas abandonaram uma etapa da escolarizaçáo, sem concluí-la, entendemos que processos de inclusão e exclusão na escola foram vivenciados por elas antes de serem presas. O que as excluiu da etapa da escolarização que haviam iniciado? Em alguns casos foi a própria detenção, em outros, como analisaremos mais adiante, foram processos de discriminação, a baixa condição econômica e a condição feminina.

Outra característica que marca esse grupo de mulheres é a maternidade, conforme retratado no Gráfico 2. 


\section{Gráfico 1}

Nível de escolaridade das mulheres entrevistadas.

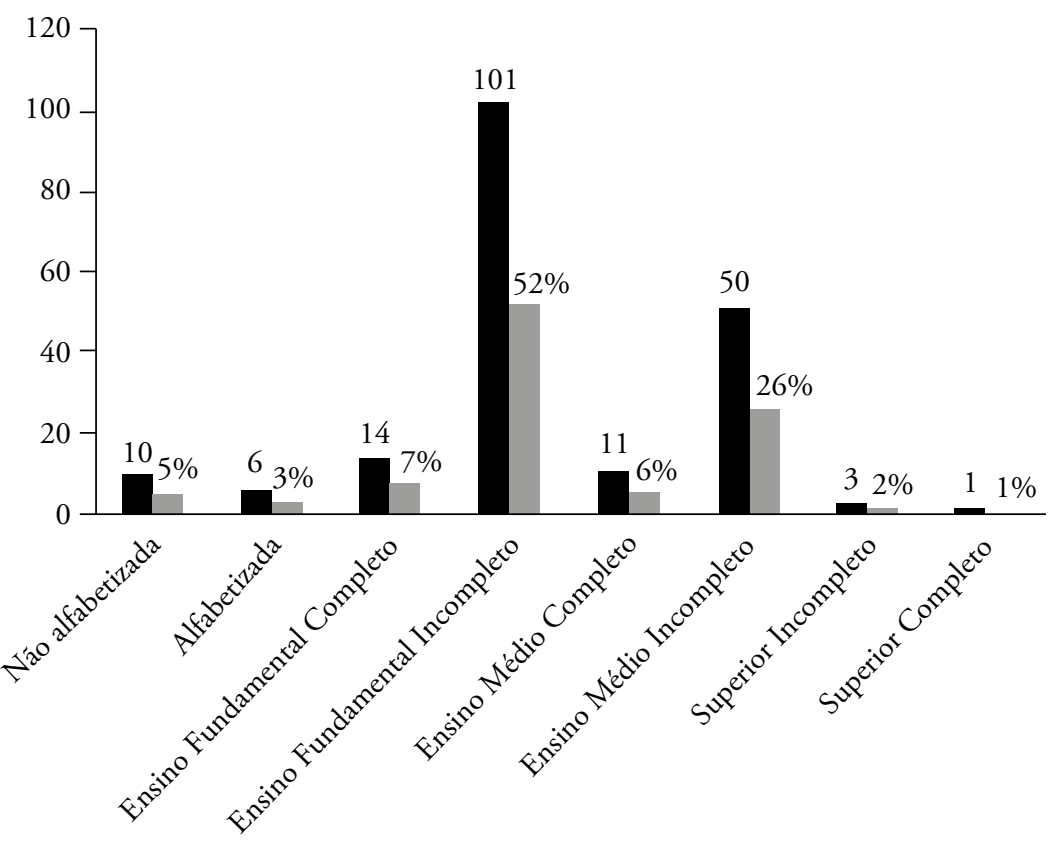

Fonte: Dados da Pesquisa de Campo, 2013.

\section{Gráfico 2}

Situação das mulheres entrevistadas em relação à maternidade.

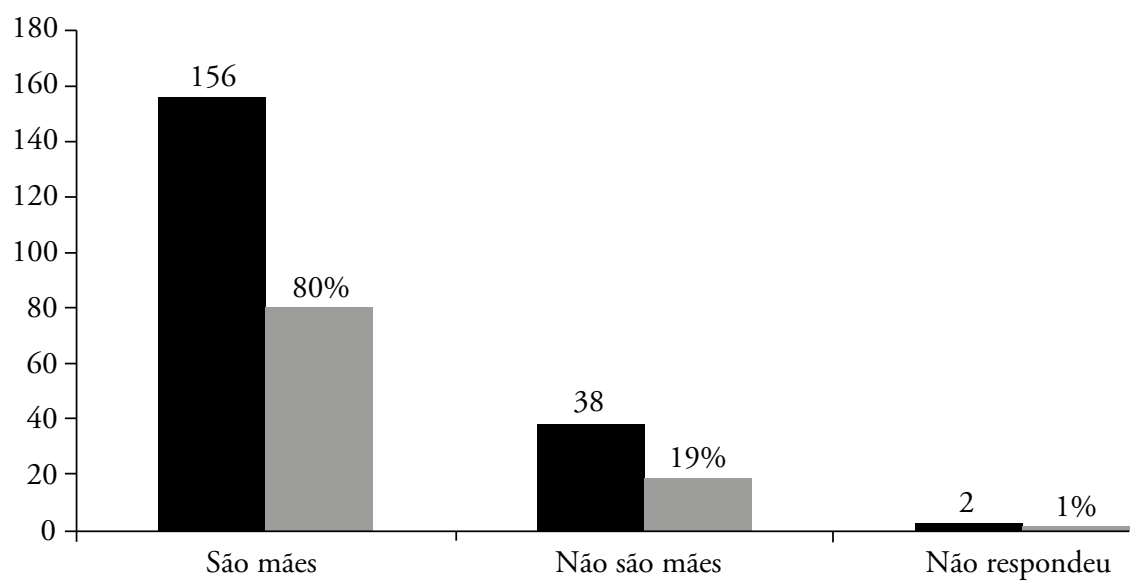

Fonte: Dados da Pesquisa de Campo, 2013. 
No conjunto das mulheres entrevistadas, encontram-se $80 \%$ (156 mulheres) que são mães. A maioria das mulheres presas convive, portanto, com o impedimento da presença cotidiana ao lado de filhos e filhas, responsabilidade que, como mostram as entrevistas realizadas com as mulheres, é passada a outras pessoas, muitas vezes suas próprias mães. Essa exclusão, em função do cumprimento da pena, da vivência tradicional da maternidade, não as impede de desenvolver um modo próprio de cuidado com os(as) filhos(as), seja por aconselhamento nos encontros que ocorrem nos dias de visita, seja pelo envio de cartas ou pela ajuda financeira que enviam às famílias, quando trabalham na prisão. Das mulheres entrevistadas que são mães, 67 declararam-se provedoras e 68 afirmaram compartilhar as despesas da casa com outras pessoas. Nesse sentido, apesar de excluídas do contato com filhos e filhas, elas prosseguem incluídas na condição de responsáveis por sua manutenção.

Os dados apresentadados indicam, portanto, um perfil jovem, com trajetórias educacionais interrompidas, presença de mulheres não alfabetizadas, grande número de mulheres com o Ensino Fundamental incompleto e a responsabilidade pela manutenção e os cuidados com os(as) filhos(as). Tal perfil, corroborado por outros estudos que discutem o encarceramento feminino (GRACIANO; SCHILLING, 2008; NONATO, 2010, 2011; CUNHA, 2010; SANTA RITA, 2013; BRASIL, 2014), remete a outras realidades de exclusão, além da ausência de liberdade; e a processos de inclusão dela decorrentes. Uma vez na prisão, as mulheres constroem outras formas de inclusão nos contextos da maternidade e da escolarização.

\section{Educação na prisão: entre a inclusão e a exclusão}

O arcabouço teórico apresentado na introdução deste artigo explicita o direito à educação na prisão. Tendo como referência esse princípio, foram pesquisadas as condiçóes nas quais se desenvolvem as experiências educacionais das mulheres em situação de privação de liberdade ${ }^{1}$, o que revelou situaçóes diversas: oferta náo estruturada; oferta de escolarização no nível dos anos finais do Ensino Fundamental; oferta de escolarização no nível do Ensino Fundamental completo; e oferta de escolarização da Educação Básica (Ensino Fundamental Completo ao Ensino Médio). Apresentamos a seguir esses diferentes contextos:

\section{Instituição A}

Nesta instituição, com capacidade de atendimento para 30 mulheres, a oferta da educação é baseada no voluntariado de professores que atendem a demandas de alfabetização e de ensino dos conteúdos da Educação Básica. Por tratar-se de ensino não formal, não há sistematização de conteúdo, de carga horária ministrada, de periodicidade, controle de frequência ou perspectivas de conclusão de estudos, e a oferta educacional fica condicionada à possibilidade de contribuição dos voluntários. 


\section{Instituição B}

$\mathrm{Na}$ instituição B acontece desde 2009 a escolarização formal nos anos iniciais do Ensino Fundamental, por meio da oferta pela rede municipal de educação de uma turma de EJA.

$\mathrm{O}$ acesso das mulheres à escola se faz desde o momento em que ingressam na instituição. Ao ser identificado pelo serviço de assistência social que a ingressante não completou o Ensino Fundamental, ela é encaminhada à escola. As aulas acontecem de segunda a sexta-feira e têm duração de 2 horas e meia, atendendo ao denominado pela escola: $1^{\mathrm{o}}$ segmento $\left(5^{\mathrm{a}}\right.$ e $6^{\mathrm{a}}$ séries) e $2^{\mathrm{o}}$ segmento $\left(7^{\mathrm{a}}\right.$ e $8^{a}$ séries). A aluna cursa um segmento por ano. Trabalham nessa oferta educacional professores de Ciências, Matemática, Inglês, Educação Física e professoras de Português, História/Geografia.

A educação acontece separadamente, no espaço da instituição prisional, conforme o tipo de regime: fechado ou semiaberto ${ }^{2}$. As mulheres do regime semiaberto dirigem-se sozinhas às salas de aula, e não há normas de segurança mais rígidas. No regime fechado, são os professores que se deslocam para a sala de aula que funciona nesse espaço. A pedagoga responsável afirma que não há um projeto pedagógico específico e que são seguidas as orientaçóes gerais da EJA na rede municipal.

Participavam da escola, à época da pesquisa, 15 das 42 mulheres presas. A demanda de escolarização nos anos iniciais do Ensino Fundamental era apresentada por duas mulheres, mas não era efetivamente atendida, pois não havia professores específicos dessa etapa. Durante as entrevistas, as mulheres que já haviam concluído o Ensino Fundamental, algumas na própria instituição, solicitaram a oferta do Ensino Médio, ou a possibilidade de matrícula em escolas estaduais. Existe também a organização para saída diária da instituição para cursar o Ensino Superior, o que era realizado por uma mulher.

\section{Instituição C}

Nessa instituição, com uma população de 125 mulheres, 74 estudam. A escola está vinculada à rede estadual de ensino e organizada em Ensino Fundamental e Médio, em dez turmas — da alfabetização ao terceiro ano do Ensino Médio ${ }^{3}$.

A entrada na escola acontece quando as mulheres são recebidas na instituição, depois de uma entrevista inicial com a pedagoga. Elas permanecem na escola por duas horas e meia, semanalmente, mas as aulas podem eventualmente ser suspensas em função de procedimentos de segurança, situação bastante comum, segundo a pedagoga. Ainda segundo essa profissional, as aulas podem ocorrer apenas no horário diurno, pois à noite seria mais difícil garantir os referidos processos de segurança no deslocamento das alunas. Também nessa instituição não há um projeto pedagógico específico. 


\section{Instituição D}

Essa instituição conta com uma população de 365 mulheres, das quais 118 cursavam o Ensino Fundamental, organizado em $1^{\circ}$ e $2^{\circ}$ segmentos em três períodos anuais, ou Ensino Médio em um período anual ( $\left.1^{\circ} \mathrm{ano}\right)$ e dois períodos semestrais $\left(2^{\circ}\right.$ e $3^{\circ}$ anos).

A oferta de escolarização é contemplada em projeto pedagógico próprio que estabelece as diretrizes para o funcionamento da escola. Segundo esse documento, a capacidade da escola é de 123 alunas, podendo ser aumentada de acordo com o interesse da instituição prisional, que deverá prover mais espaço para a organização das salas ou viabilizar outros turnos de funcionamento. As aulas acontecem entre $18 \mathrm{~h}$ e $20 \mathrm{~h} 30$. Havia também uma turma funcionando no horário vespertino.

A pedagoga da unidade explica que a matrícula é aberta durante o ano todo. Para a candidata ingressar na escola, essa profissional verifica se ela possui o Procedimento Interno de Ressocialização (PIR) e, em caso positivo, dá prosseguimento à matrícula e à verificação da documentação escolar. Se a candidata não possui o PIR, seu nome é encaminhado à Comissão Técnica para análise e, com o aval dessa comissão, ou da Direção Geral da Instituição Prisional, a escola efetua a matrícula.

O projeto pedagógico prevê a transferência de alunas que estejam estudando em outras unidades prisionais, as quais, após o período de triagem na instituição, poderão matricular-se para dar prosseguimento aos estudos. $\mathrm{O}$ desligamento da estudante da escola por determinado número de ausências não justificadas também é previsto no projeto. A frequência mínima de $75 \%$ é obrigatória para fins de promoção. O projeto prevê o aproveitamento de estudos em cursos legalmente autorizados e processos de classificação para a análise da turma à qual a estudante se vinculará.

São, pois, heterogêneas as condições da oferta de escolarização para mulheres em situação de privação de liberdade em instituições exclusivamente femininas no estado de Minas Gerais. Duas instituiçôes ofertam possibilidades mais amplas de escolarização, enquanto em outras a oferta é restrita e, em um caso, apenas informal. As visitas para a coleta de dados possibilitaram observar que o funcionamento das "escolas" das prisóes é determinado pelas normas, rituais e hierarquias das instituições, como descreve Foucault (1987). Podemos dizer também que a escolarização não alcançou a perspectiva de um direito pleno, pois não estão garantidas as condições de continuidade dos estudos em nível médio em todas as instituiçóes.

Pode-se afirmar, portanto, que apesar dos avanços em termos de reconhecimento e expansão, o direito à educação de pessoas em situação de privação 
de liberdade ainda náo se traduz em propostas efetivas que alcancem a todas. No que tange a esse direito, é imperativo lembrar que, como mulheres adultas, na condição de estudantes da EJA, elas deveriam ser incluídas na escola, pois,

\begin{abstract}
não pode haver exclusão decorrente de idade, gênero, etnia, condição de imigrante, língua, religiâo, deficiência, ruralidade, identidade ou orientação sexual, pobreza, deslocamento ou encarceramento. É particularmente importante combater o efeito cumulativo de carências múltiplas. Devem ser tomadas medidas para aumentar a motivaçáo e o acesso de todos (UNESCO, 2010, p. 11).
\end{abstract}

Portanto, a oferta educacional nessas instituiçóes significa possibilidade e limite da educação, oferta e negação do direito de estudar, inclusão e exclusão. Possibilidade e inclusão na medida em que algumas instituiçóes garantem Ensino Fundamental e Ensino Médio, com a realização de atividades educativas escolares de maneira regular e com certificação. Limite e exclusão em relação à não oferta dos níveis educacionais posteriores, nem na própria instituiçâo nem em instituições externas. Os limites aparecem também na medida em que todas as ofertas educacionais pesquisadas estão submetidas às normas da prisão (as quais, muitas vezes, não coincidem com as possibilidades dos processos educativos). É, pois, nesse contexto que muitas mulheres adentram as salas de aula, e a decisão de estudar na prisão carrega as marcas de processos de inclusão e exclusão.

\title{
Estudar na prisão: processos de inclusão e exclusão
}

O período de aprisionamento é uma parte da vida das mulheres durante a qual elas são excluídas do convívio social mais amplo e incluídas em outro espaço, marcado pela restrição da liberdade. É nesse espaço de inclusão restrita que elas vivenciam novamente, ou pela primeira vez, a experiência educativa. Para compreender como essa experiência se relacionava às vivências escolares anteriores e a seus projetos de vida, como "mulheres em situação de privação de liberdade", foram realizadas entrevistas semiestruturadas com 11 mulheres, escolhidas entre as que frequentavam a escola em duas das instituiçóes pesquisadas ${ }^{4}$.

A análise dos relatos das mulheres permite identificar as marcas da exclusão escolar, da maternidade, da relaçáo com o conhecimento e da condição de aprisionamento, engendrando processos de inclusão e exclusão. Como alunas da EJA, essas mulheres apresentam a condição de excluídas da escola regular (OLIVEIRA, 2001). Duas delas, habitantes do campo, não tiveram acesso à educação e desde cedo se viram envolvidas na "lida da roça" - "trabalhava na roça pra ajudar a criar os meus irmãos" (E15 , 58 anos); outras seis mulheres tiveram a trajetória escolar interrompida, retornando à escola na prisão para concluir os anos iniciais ou finais do Ensino Fundamental. A inserçâo no mercado de trabalho foi apontada 
por sete delas como causa da interrupção da trajetória escolar. Nos relatos, é possível conferir a necessidade do trabalho em detrimento da escola: "[com 11 anos] comecei trabalhar na casa de família" (E2, 54 anos); "foi muito sofrimento na minha infância, então eu desisti da escola, fui trabalhar, saí da escola" (E3, 40 anos); "aí eu fiquei sem estudar, comecei a trabalhar. Quando eu completei meus 12 anos eu saí de casa pra trabalhar de doméstica na casa dos outros" (E4, 40 anos).

Essas mulheres encontravam-se, como crianças e adolescentes, enredadas nas tramas da desigualdade social, e a luta pela sobrevivência levou-as a uma inclusão precoce e precária no mundo do trabalho. Além das tramas da desigualdade social, encontram-se também enredadas nas tramas da desigualdade de gênero, ao terem que assumir, ainda na adolescência, os cuidados com os(as) filhos(as). Como adolescentes mulheres, assumem a gravidez precoce, sem o apoio do pai da criança, e desistem da escola: "entrei na escola eu tava com sete anos, aí eu fiz a $1^{\text {a }}$, a $2^{\mathrm{a}}$, a $3^{\mathrm{a}}$, a $4^{\mathrm{a}}$. Aí passei pra $5^{\mathrm{a}}$ e saí da escola, parei de estudar, comecei a trabalhar (...) Tinha minha filha! Como o pai dela nunca tinha dado nada...” ${ }^{6}$ (E5, 40 anos); "eu parei de estudar eu tinha 14 anos (...) porque eu fiquei gravida, né" (E6, 43 anos). Podemos ler no relato da entrevistada E6 a perpetuaçáo da desigualdade de gênero no tocante à responsabilidade da mulher, por vezes exclusiva, no cuidado com os(as) filhos(as). A situaçáo vivida por ela foi também vivenciada por suas duas filhas - ambas pararam de estudar para trabalhar e assumir os filhos, ainda adolescentes. Uma das filhas, que também se encontra na prisão, relata: "Comecei a estudar aos 7 anos de idade e eu estudei muito, mas eu parei aos 14 anos [8 $8^{\mathrm{a}}$ série] porque eu engravidei" (E7, 21 anos).

Como mulheres, elas também vivenciaram relações conturbadas com os companheiros - de abandono, negligência e, em alguns casos, violência doméstica: "Ele tentou me matar, a minha menina veio me acudir, ele pegou a minha menina" (E2, 54 anos). Os relatos dessas mulheres expóem as desigualdades históricas de gênero, há muito denunciadas pelas estudiosas feministas e que continuam a marcar as trajetórias das mulheres, limitando, e por vezes cerceando, o acesso à educação.

Ainda outra desigualdade compóe as marcas da exclusão escolar: a desigualdade racial. Uma das mulheres entrevistadas (E3, 40 anos) relata que estudou até a $5^{\text {a }}$ série, parou de estudar e começou a trabalhar para ajudar a mãe alcoólatra no cuidado com os irmãos, mas carrega ainda hoje as marcas dessa desigualdade: "A gente era assim a cor negra foi muito discriminada na época de escola né? Entáo, os meninos mexia demais comigo né? Me xingava de nega do cabelo seco. Isso acontece até hoje né?". A desigualdade racial acompanha as mulheres na prisão: "duas em cada três presas são negras" (BRASIL, 2014, p. 24).

Assim, excluídas precocemente da escola pelas desigualdades sociais, de gênero e de raça, 8 das 11 mulheres entrevistadas se veem na prisão incluídas novamente no espaço escolar. Para as outras três, entretanto, o aprisionamento interrompe trajetórias escolares de sucesso e as coloca, até que retomem novamente 
os estudos na prisão, na condição de excluídas da escola. Duas puderam frequentar o Ensino Médio e esperavam concluí-lo, mas para uma delas, que retornou na $8^{\text {a }}$ série, assim como para suas colegas que concluem o Ensino Fundamental, haverá a interrupção forçada da escola, pois não há a oferta do Ensino Médio assim, a prisão cerceará novamente a inclusão escolar, colocando-as na condição de excluídas da escola.

A condição do aprisionamento também engendra, nas vivências escolares das mulheres presas, processos de exclusão e inclusão. Para as mulheres que cedo se viram forçadas a abandonar a escola, frequentar a escola na prisão é vivenciar um processo de inclusão que resgata um direito negado. Esse direito é traduzido por elas "como um sonho" (E1, 58 anos); "oportunidade, já que antigamente os pais não deixavam menina mulher sair" (E8, 50 anos); "oportunidade, porque lá fora não tem jeito, é difícil, trabalhar, cuidar dos filhos" (E3, 40 anos); "[Não iria estudar fora da prisão] porque a primeira coisa que eu ia pensar ia ser nas minhas filhas, não deixar faltar nada pra elas" (E5, 40 anos). Para as mulheres que tiveram a trajetória escolar interrompida pela condição do aprisionamento, retornar à escola é a possibilidade de retomar uma oportunidade que consideram ter "desperdiçado": “(...) Eu perdi a oportunidade e eu não me imaginava estudando mais. Vou ser bem sincera, quando eu tava na rua eu não me imaginava estudando mais. A vida que eu estava levando, as companhias, tudo fazia com que eu pensasse em não estudar" (E10, 21 anos).

Estudar é, pois, para elas, assim como para as mulheres alunas da EJA (FONSECA, 2005), um ato de cuidado consigo mesmas. É o momento no qual, excluídas do convívio familiar, apostam na escolarizaçáo como cuidado, voltam a pensar em si, e a escola se insere nos seus projetos futuros, seja de trabalho, seja de reconhecimento familiar: "Quando eu sair daqui mostrar lá pra fora, mostrar pra eles, né. Até meus parentes mesmo que, tipo assim a mudança. A mudança não é convivência, a mudança é diferença, como eu tive a capacidade de aprender, sabe? De ser alguma coisa pra mostrar pra minhas filhas também isso" (E4, 34 anos). Estudar é a aposta de que "o outro" as veja como alguém diferente. Uma das entrevistadas relata o orgulho do pai e da mãe quando ela concluiu, na prisão, o Ensino Médio, que possibilitou inclusive reaproximar-se da família: "[Meu pai falou]: 'Minha filha, eu tô muito feliz com você. Não acha que eu não tô acompanhando não, que eu tô acompanhando sim"'; "Minha mãe veio na formatura e falou assim: 'No momento da formatura foi a mesma sensação que eu senti quando você nasceu" (E11, 23 anos).

Se a condição de aprisionamento possibilita a inclusão escolar, também cerceia o acesso à escola. $\mathrm{Na}$ relação com a escola, podemos encontrar as marcas dessa condição. Os relatos das mulheres são pontuados pelo não acesso à escola - a trajetória delas nessa condição produz inicialmente o cerceamento escolar: porque aguardam definiçôes de pena; porque transitam entre instituiçôes; porque 
aguardam o cumprimento de procedimentos burocráticos; porque aguardam avaliação por bom comportamento; ou porque estavam em uma instituição na qual a possibilidade de estudar não se apresentava: "Não vou dizer que aqui é um mar de rosas [a instituição atual], mas aqui é bem diferente de lá [cadeia pública], eu comecei a estudar" (E2, 54 anos). O cerceamento se liga também às condiçóes do aprisionamento: há diferenças entre as instituiçôes prisionais e as regras a cumprir:

...De lá eu fui transferida pra cadeia. Depois fui pra outra [instituição]. Aí, com duas semanas que eu tava lá, eles perguntaram se eu queria vim pra cá. Que aqui era bom, que aqui eu ia pegar em garfo e colher, e prato, né? Copo de vidro, coisas que lá na cadeia a gente não via, né? Esses dois anos eu vivia uniformizada, aqui ia vestir roupa normal, que aqui eu tinha todos os meus direitos. Aí eu assinei o termo e vim. Vai fazer nove meses que eu tô aqui agora (...). E aqui é muito bom para pagar a cadeia, minha mente mudou totalmente (E4, 34 anos).

Assim como a prisão, compreendida no sentido foucaultiano como um aparato disciplinador e normalizador (FOUCAULT, 1987), a escola na prisão também assume essa configuração. Os relatos das entrevistadas evidenciam aprisionamentos dessa escola (com seus códigos e regras de conduta) que ecoam nas práticas educativas: nas relaçōes entre docentes e discentes; nas relaçōes das alunas entre si; nas formas de organização do espaço; nas diferentes funçôes e sentidos da escolarização (para o sistema prisional e para as mulheres); e nas visóes que prevalecem sobre a educação na prisão com o objetivo de "recuperação do apenado" (JULIÃO, 2013a, p. 8).

$\mathrm{Na}$ configuração da escola como esse aparato disciplinador, o estudo se alia ao trabalho e à religião, e estudar não configura uma opção, mas uma obrigação. Ser aluna significa ser vista de outro modo - como alguém que quer se recuperar e é disciplinado, tem bom comportamento:

Se eu sair daqui da escola, a professora tá dando aula aqui, aí a gente sai e vai lá pro canto. Aí, não sei quem não, tem um vigia na área, aí vai lá e conta. Conta: "Fulana tá lá, em tal lugar assim, assim”. Aí ela vem [a responsável] e pergunta: "Por que que você tá aqui?" "É porque eu quero". Já passa a mão em nós e já sai arrastando nós. Misericórdia, sai arrastando e leva pro quarto e aplica em nós um comunicado [uma disciplina]. Dez comunicados por causa da escola, a escola é muito importante; é isso. Esses dias a [...] tava dormindo. Aí a mulher [agente] pegou ela e deu ela dez dias de castigo [na cela]. A gente tem que ser depois, deixar a vez deles primeiro, tem que ser a última a falar. Fala quem pode e obedece quem tem juízo, porque a gente tem que ficar calado, abaixar a cabeça como se não tivesse falando nada com a gente. Entendeu? (E9, 50 anos). 
Estabelece-se, por um lado, uma relação de tensões advindas do espaço da prisão sobre o espaço da escola; por outro lado, ao se incluírem no espaço escolar, a exclusão dos outros espaços sociais e os efeitos do cerceamento característicos da prisão parecem minimizados, e elas assumem a condição de estudantes cujas demandas, anseios e necessidades são acolhidos pelos professores. Nos relatos das entrevistadas, a relação pedagógica se sobressai na pessoa do(a) professor(a): "Eles explicam à gente, tem dia que a gente tá triste. Oh! Tô te achando táo triste. Você não é assim! Sabe? Tentam trazer uma palavra de conforto" (E5, 40 anos); "Eu fui pro castigo e fiquei confinada. Aí você vai pra escola você aprende, foi aonde me ajudou bastante, entendeu? Assim que eu saí do castigo eu comecei a estudar, entáo eu tava muito abalada, eu chorava muito, entáo foi a escola que me deu o maior apoio que eu tive aqui dentro (E10, 21 anos).

No projeto de vida das mulheres, a saída da prisão é o horizonte a ser alcançado e, nesse sentido, "a remição [da pena] na escola conta muito" (E6, 43 anos); porque "na escola cai um sexto da minha pena" (E3, 40 anos); por isso vai-se à escola, mas há também as marcas da relaçáo com o conhecimento escolar pautando os processos de exclusão/inclusão escolar. As mulheres que abandonaram cedo a escola carregam para a sala de aula desconfiança sobre a sua competência em aprender e se surpreendem com seu desempenho escolar: "Achei que eu não conseguia"; "que eu não tinha cabeça"; "espantei quando aprendi" são expressóes que evocam as marcas da exclusão escolar na relação com o conhecimento que se apresenta em estudantes da EJA (OLIVEIRA, 2001) e nessas mulheres. Mas outras marcas também se apresentam, e há diferentes sentidos para o aprender na escola: "ler a Bíblia"; "escrever minhas cartas"; "aprender matemática"; "aprender história"; "comunicar melhor"; "aprender outro jeito de falar"; aprender para compreender a "situação da pena"; "interpretar textos"; "fazer ofício"; "ter boa gramática"; "ler"; "ler romances"; "aprender da área jurídica”. Essas aprendizagens se inscrevem na experiência atual, mas se relacionam a seus projetos futuros de retomada da vida familiar, de retomada profissional e de retomada dos estudos, como o desejo de "cursar uma faculdade" (E10; E11). Fazem parte, portanto, das situaçóes que revelam o binômio inclusão/exclusão na vida das mulheres que conhecemos na pesquisa realizada: na escola, na prisão, na escola da prisão.

\section{Conclusão}

As mudanças na legislação brasileira acenam para a possibilidade de a educação prisional no Brasil se estruturar, nos próximos anos, para o atendimento a um contingente crescente de população (JULIÃO, 2013b). Há hoje a deliberação de um arcabouço legal que reconhece o direito à educação nesse contexto, e busca-se avançar na implementação de políticas públicas que o assegurem efetivamente. 
Corroborando o exposto acima, constata-se neste estudo a ampliação do acesso à educação das mulheres pela oferta de EJA nas instituiçóes prisionais. Entretanto, tal oferta não se estende ainda a todas as quatro instituiçóes analisadas e, mesmo quando ocorre, o acesso ainda não se faz de modo igualitário para todas as mulheres, em função dos cerceamentos próprios da prisão.

Ao trazer à cena as narrativas das mulheres, evidencia-se a perspectiva dos sujeitos que vivenciam, em meio à situação de privaçâo da liberdade, a experiência escolar e as lógicas da exclusão/inclusão que a permeiam. Para um grupo de mulheres, é o retorno a um direito negado que reencontram no contexto prisional; para outras, a situação do aprisionamento significa exclusão da possibilidade de prosseguir os estudos. Nos processos escolares das mulheres presas encontram-se engendradas as marcas da exclusão escolar, da maternidade, das desigualdades sociais, de gênero e raciais e da violência contra a mulher, no contexto da condição de aprisionamento. Ao compreender esse processo pela lógica das categorias inclusão e exclusão, podemos pensar que, ao serem excluídas da convivência social, as mulheres apenadas são inseridas no subsistema prisional, que pretensamente deveria se valer do tempo para prepará-las para uma nova inclusão na vida em sociedade. Há possibilidades de inclusão na escola da prisão permeadas por realidades que significam novas experiências de exclusão, visto que não encontramos em todas as instituiçóes prisionais exclusivamente femininas do estado de Minas Gerais a oferta da escolarização, e nenhuma delas garante a continuidade da escolarização para todas as detentas: não há vagas para todas, e os projetos educativos desenvolvidos nem sempre atendem a necessidade de formação específica dessas mulheres.

A populaçáo aprisionada, em sua maioria, mostra-se fortemente atingida pela desigualdade social, em termos de renda, de acesso a bens culturais, educaçáo, trabalho, saúde etc. Por isso, a educação pode se revestir de um sentido de inclusão, no reconhecimento da dimensão pessoal, pelo fortalecimento da autoconfiança, pela determinação pessoal e, também, pelos sentidos que as pessoas nessa situação atribuem ao retorno à escola. Nessa perspectiva, a educação em espaço prisional adquire pleno sentido, pois possibilitaria à população carcerária ser incluída em outro universo ligado à identidade, ao cuidado pessoal, ao conhecimento e também à qualificação profissional, uma vez que é concebida com a finalidade de investir a pessoa de possibilidades para continuar a viver na sociedade de forma digna. Com efeito, a escola na prisão pode significar a saída de uma inexistência decretada pela linha abissal para uma existência reconhecida e legitimada pela sociedade.

\section{Notas}

1. Condições identificadas por meio de entrevistas com três pedagogas que acompanhavam as experiências educacionais em três instituiçôes, um diretor de outra instituição e análise de projetos pedagógicos. 
2. A pena privativa de liberdade será executada em forma progressiva: do regime mais rigoroso (fechado) para o regime menos rigoroso (semiaberto e aberto), conforme artigo 112 da LEP.

3. São quatro turmas dos anos iniciais, quatro turmas dos anos finais e duas turmas do Ensino Médio.

4. A escolha das mulheres contemplou diferentes faixas etárias e diferentes níveis de escolaridade, sem pretender gerar uma amostra representativa.

5. Entrevistada.

6. As falas das entrevistadas foram mantidas sem correçôes linguísticas.

\section{Referências}

BRASIL. Lei no 7.210, de 11 de julho de 1984. Institui a Lei de Execução Penal. Disponível em: http://www.planalto.gov.br/ccivil 03/leis/L7210.htm. Acesso em: 9 set. 2015.

Lei $\mathrm{n}^{\circ} 12.433$, de 29 de junho de 2011. Altera a Lei $\mathrm{n}^{\circ} 7.210$, de 11 de julho de 1984 (Lei de Execução Penal), para dispor sobre a remição de parte do tempo de execução da pena por estudo ou por trabalho. Disponível em: http://www.planalto.gov.br/ ccivil 03/ ato2011-2014/2011/lei/112433.htm. Acesso em: 10 jan. 2016.

. Constituição (1988). Constituição da República Federativa do Brasil. Brasília, DF: Senado Federal, 1988.

Lei no 9.394, de 20 de dezembro de 1996. Estabelece as diretrizes e bases da educação nacional. Diário Oficial da União, Brasília, DF, 23 dez. 1996. Disponível em: https://www.planalto.gov.br/ccivil 03/Leis/L9394.htm. Acesso em: 20 dez. 2015.

Resolução CNE/CEB no 2, de 19 de maio de 2010. Dispóe sobre as Diretrizes Nacionais para a oferta de educaçáo para jovens e adultos em situaçáo de privação de liberdade nos estabelecimentos penais. Diário Oficial da União, Brasília, DF, 20 mai. 2010, Seção 1, p. 20.

Ministério da Justiça. Levantamento Nacional de Informaçóes Penitenciárias: INFOPEN Mulheres - Junho de 2014. Brasília, DF: Ministério da Justiça, 2014.

CARRREIRA, D. Relatoria Nacional para o Direito Humano à Educação: Educação nas Prisóes Brasileiras. São Paulo: Plataforma DhESCA, 2009. Disponível em: http://www. dhescbrasil.org.br. Acesso em: 6 ago. 2015.

CUNHA, E.L. Ressocialização: o desafio da educação no sistema prisional feminino. Cadernos CEDES, Campinas, vol. 30, n. 81, p. 157-178, mai./ago. 2010. Disponível em: http://www.cedes.unicamp.br. Acesso em: 7 dez. 2015.

DUPAS, G. Economia global e exclusão social: pobreza, emprego, estado e o futuro do capitalismo. São Paulo: Paz e Terra, 1999.

FONSECA, M.C.F.R. Educação matemática de jovens e adultos: especificidades, desafios e contribuições. Belo Horizonte: Autêntica, 2005. 
FOUCAULT, M. Vigiar e Punir: nascimento da prisão. 27a ed. Petrópolis: Vozes, 1987.

GRACIANO, M.; SCHILLING, F. A educação na prisão: hesitações, limites e possibilidades. Estudos de Sociologia, Araraquara, v. 13, n. 25, p. 111-132, 2008.

IRELAND, T.D. Educação em prisões no Brasil: direito, contradiçóes e desafios. Em Aberto, Brasília, v. 24, n. 86, p. 19-39, nov. 2011. Disponível em: http://emaberto. inep.gov.br/index.php/emaberto/issue/view/252. Acesso em: 26 out. 2016.

JULIÂO, E.F. Educação de jovens e adultos no sistema penitenciário: notas de pesquisa sobre a experiência brasileira. Arquivos Analíticos de Políticas Educativas, v. 21, n. 75. p. 1-23, set. 2013. Disponível em: http://epaa.asu.edu/ojs/article/download/1314/1149. Acesso em: 6 dez. 2015.

- (Org.). Educação para jovens e adultos em situação de restrição e privação de liberdade: questóes, avanços e perspectivas. Jundiaí: Paco Editorial, 2013.

MARTINS, J.S. Exclusão social e a nova desigualdade. São Paulo: Paulus, 1997.

A sociedade vista do abismo: novos estudos sobre exclusão, pobreza e classes sociais. Petrópolis, RJ: Vozes, 2002.

MØLLER, I.H., HESPANHA, P. Padrões de exclusão e estratégias pessoais. Revista Crítica de Ciências Sociais, Coimbra (Portugal), n. 64, p. 55-79, dez. 2002. Disponível em: http:// www.ces.uc.pt/rccs/index.php?id=806\&id lingua=1. Acesso em: 9 mai. 2015.

NONATO, E.M.N. Educação de mulheres em situação prisional: experiência que vem do sul, no processo de reinvenção social. 2010. 198f. Tese (Doutorado em Ciências Sociais) Universidade do Vale do Rio dos Sinos, São Leopoldo, 2010.

Educação de mulheres em situação de privação de liberdade. Em Aberto, Brasília, v. 24, n. 86, p. 127-140, 2011. Disponível em: http://emaberto.inep.gov.br/index.php/ emaberto/issue/view/252. Acesso em: 15 dez. 2015.

OLIVEIRA, M.K. Jovens e adultos como sujeitos de conhecimento e aprendizagem. In: RIBEIRO, V.M. (Org.) Educação de jovens e adultos: novos leitores, novas leituras. São Paulo: Ação Educativa, 2001. p. 15-43.

SANTA RITA, R.P. Filhos de mulheres em situação de privação de liberdade: como se desenvolve a Educação Infantil em ambiente penitenciário? In: JULIÃO, E.F. (Org.). Educação para jovens e adultos em situação de restrição e privação de liberdade: questóes, avanços e perspectivas. Jundiaí: Paco Editorial, 2013. p. 107-124.

ORGANIZAÇÃO DAS NAÇÓES UNIDAS PARA A EDUCAÇÃO, A CIÊNCIA E A CULTURA (UNESCO). CONFINTEA VI: sexta conferência internacional de educação de adultos. Marco de Ação de Belém. Brasília, DF: UNESCO, 2010.

Recebido em 15 de janeiro de 2016.

Aprovado em 29 de setembro de 2016. 